\title{
Expression and Distribution of Galectin-3 in Chromophobe and Papillary Carcinomas
}

\author{
ANDREEA CIOCA ${ }^{1}$, DIANA MUNTEAN ${ }^{2}$, CATALINA BUNGARDEAN ${ }^{2}$, \\ MARIUS RAICA $^{1}$ and ANCA MARIA CIMPEAN ${ }^{1}$ \\ ${ }^{1}$ Department of Histology, Angiogenesis Research Center, \\ "Victor Babes" University of Medicine and Pharmacy, Timisoara, Romania; \\ ${ }^{2}$ Department of Pathology, Regional Hospital, Cluj-Napoca, Romania
}

\begin{abstract}
Background/Aim: Probably due to their low occurrence, chromophobe and papillary renal cell carcinomas are less well characterized and, currently, there are no reliable prognostic markers for this group of patients. Moreover, the optimal therapy for patients with non-clear renal cell carcinoma $(R C C)$ is unknown yet. Although elevated levels of Galectin-3 (Gal-3) were associated with poor prognosis in conventional RCC, the impact of this protein on carcinogenesis of chromophobe and papillary entities has not been previously described. Materials and Methods: Gal-3 expression was investigated in 34 consecutive cases of RCCs, including 19 papillary carcinomas and 15 chromophobe carcinomas. Results: Immunohistochemical analysis of Gal-3 in tumor cells showed 3 patterns of expression: membranous, cytoplasmic and nuclear staining. Most tumors included in our study showed a cytoplasmic expression and it was almost equally distributed between the histologic subtypes. However, only nuclear staining of Gal-3 was associated with both Fuhrman grade and tumor stage ( $p=0.016$ and $p=0.032$, respectively) in chromophobe subtype. Conclusion: Our results indicate that the nuclear expression of Gal-3 has an essential role in the development of chromophobe carcinoma. The association with advanced tumor stage and nuclear grade suggests that this protein is an indicator of aggressiveness in the chromophobe subtype, thus targeting anti-nuclear transport may prove an effective therapy for this particular group of patients.
\end{abstract}

Correspondence to: Assistant Professor Andreea Cioca, Department of Microscopic Morphology/Histology, Angiogenesis Research Center, "Victor Babes" University of Medicine and Pharmacy, Piata Eftimie Murgu 2, 300041 Timisoara, Romania. Tel: +40 722244330, e-mail: cioca_andre@yahoo.com

Key Words: Galectin-3, immunohistochemistry, chromophobe, renal cell carcinoma.
Renal cell carcinoma (RCC) is the most common kidney malignancy, accounting for $2-3 \%$ of all adult cancers. Based on the World Health Organization (WHO) classification, RCC is divided into different histologic subtypes including clear cell, papillary, chromophobe, collecting-duct and unclassified tumors (1). To date, most studies focus on clear cell carcinoma (ccRCC) which is the most common histologic type (75-80\% of all cases). Among the other subtypes, summarized as non-clear renal cell carcinomas (non-ccRCC), papillary (pRCC) and chromophobe (chRCC) variants account for $10 \%$ and 5\%, respectively (2). Probably due to their low occurrence, these specific entities are less well characterized and, currently, there are no reliable prognostic markers for this group of patients. Moreover, the optimal therapy for patients with non-ccRCC is unknown yet. Thus, elucidation of the molecular mechanism that underlies non-ccRCCs is essential for a better stratification of these patients but, also, for the development of new targeted therapies.

Galectin-3 (Gal-3) belongs to a group of b-galactoside binding proteins and is one of the most investigated members of the galectin family. This multifunctional protein regulates various physiological and pathological processes including cell growth, differentiation, apoptosis, cell adhesion, angiogenesis, inflammation, fibrogenesis and tumor progression (3-7). Gal3 was found in a relatively large spectrum of human tumors, but with a heterogenous expression that varied between different organ tissues (8). For instance, Gal-3 expression was reported to be increased in stomach, head and neck, pancreas, thyroid gland, colon and small-cell lung cancer (9-15), while a low expression of this protein was found in uterus, prostate and breast cancer (16-18).

A recent study reported that elevated levels of Gal-3 found in RCCs tissues at both mRNA and protein levels contribute to renal carcinogenesis, and concluded that this protein could be used as a therapeutic target for patients with conventional RCC (19). On the other hand, a high expression of Gal-3 was 
Table I. Galectin 3 expression in different histologic subtypes.

\begin{tabular}{lcrr}
\hline Histologic type, no & Gal-3+ cytoplasmic, no (\%) & Gal-3+ membranous, no (\%) & Gal-3+ nuclear, no $(\%)$ \\
\hline ppRCC, 19 & $16(57 \%)$ & $6(30 \%)$ & $4(30 \%)$ \\
chRCC, 15 & $12(43 \%)$ & $14(70 \%)$ & $9(70 \%)$ \\
Total, 34 & $28(82 \%)$ & $20(59 \%)$ & $13(38 \%)$ \\
\hline
\end{tabular}

Table II. Gal-3 expression of ppRCC and chRCC stratified by Fuhrman grade.

\begin{tabular}{|c|c|c|c|c|c|c|}
\hline \multirow[t]{2}{*}{ Fuhrman grade } & \multicolumn{3}{|c|}{ Papillary RCC } & \multicolumn{3}{|c|}{ Chromophobe RCC } \\
\hline & Cytoplasmic & Membranous & Nuclear & Cytoplasmic & Membranous & Nuclear \\
\hline G1 & 2 & 1 & 0 & 2 & 2 & 0 \\
\hline G2 & 12 & 5 & 4 & 7 & 8 & 5 \\
\hline $\mathrm{G} 3 / 4$ & 2 & 0 & 0 & 3 & 4 & 4 \\
\hline
\end{tabular}

Table III. Gal-3 expression of ppRCC and chRCC stratified by tumor stage.

\begin{tabular}{|c|c|c|c|c|c|c|}
\hline \multirow[t]{2}{*}{ Tumor stage } & \multicolumn{3}{|c|}{ Papillary RCC } & \multicolumn{3}{|c|}{ Chromophobe RCC } \\
\hline & Cytoplasmic & Membranous & Nuclear & Cytoplasmic & Membranous & Nuclear \\
\hline I & 9 & 3 & 1 & 5 & 4 & 2 \\
\hline II & 3 & 2 & 2 & 6 & 10 & 4 \\
\hline III/IV & 4 & 1 & 1 & 1 & 4 & 3 \\
\hline
\end{tabular}

found in the chromophobe subtype compared to papillary one, and it has been put forward as a potential marker for the differential diagnosis of RCC (20). However, the impact of this protein on carcinogenesis of chromophobe and papillary entities has not been previously described.

On this background, the aim of the present study was to evaluate both the expression and distribution of Gal-3 in 34 cases of RCC of papillary and chromophobe subtypes.

\section{Materials and Methods}

Patients and tissue samples. The tissue samples were obtained from 34 patients diagnosed with RCC in the period between 2009-2014, who underwent partial or total nephrectomy at the Regional Hospital, Cluj-Napoca, Romania. The clinicopathological data including sex, age, tumor necrosis, Fuhrman grade, tumor stage, tumor size and venous extension were recorded from the Institute's database and the pathology reports.

The local research ethics committee approved the protocol of the study and informed consent was obtained from all subjects according to the World Medical Association Declaration of Helsinki.
Immunohistochemistry. Five $\mu \mathrm{m}$ thick sections were performed from each case. The dewaxing and rehydration of the sections was followed by heat-induced epitope retrieval in citrate buffer $\mathrm{pH} 6$ for 30 min (with PT link module, Dako Cytomation, Glostrup, Denmark). The immunohistochemical technique continued with the blocking of the endogenous peroxidases, using hydrogen peroxide $3 \%$. Incubation with Galectin-3 primary monoclonal antibody (clone 9C4, dilution 1:100, Novocastra Biosystems, Newcastle uponTyne, UK) had a duration of $30 \mathrm{~min}$. The Bond Polymer Refine Detection System (Novocastra Biosystems, Newcastle uponTyne, UK) was used for visualization. 3,3 diamino-benzidine dyhidrochloride was applied as chromogen and modified Lille's hematoxylin was used for counterstain.

Image acquisition and analysis were performed using Nikon Eclipse E 600 microscope Microscopes/Instruments Division, Vienna, Austria) and Lucia G software (Laboratory Imaging, Prague, Czech Republic) for microscopic image analysis.

Evaluation of Gal-3 staining. Interpretation of immunohistochemical results were carried out by an experienced pathologist. Gal-3 was evaluated in one representative slide from each case, by selecting three areas with the highest number of positive cells (hot spot). The final score was assessed by evaluating both the intensity of the 


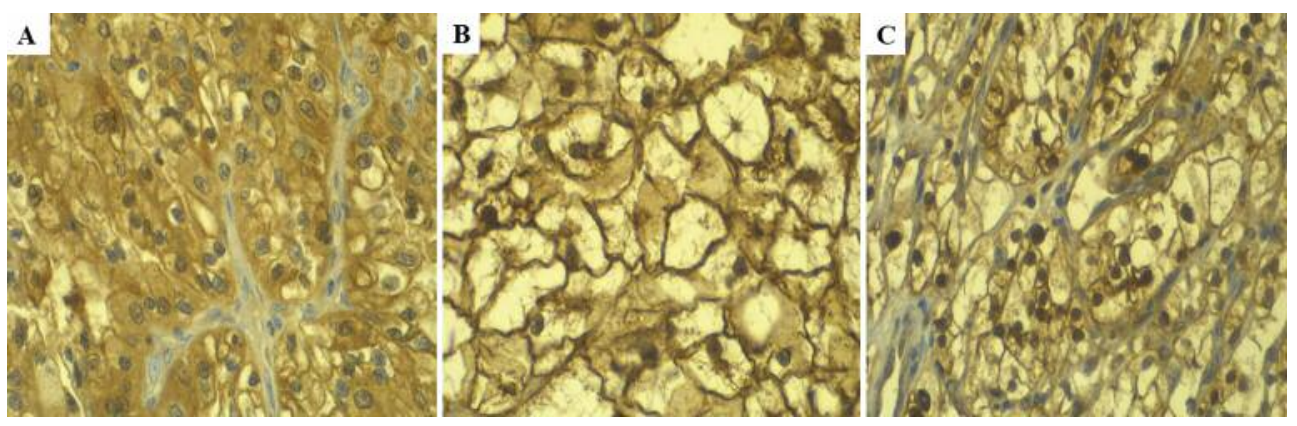

Figure 1. Variable patterns of Gal-3 expression in renal carcinoma. (A) Papillary RCC showing intense Gal-3 expression in almost all tumor cells; $(B)$ Chromophobe RCC showing intense membranous expression and moderate nuclear staining; $(C)$ Intense nuclear expression in chromophobe RCC. Original magnification $40 \times$.

immunostaining and the percent of positive cells, and was quantified on a scale of 1-3+ as follows: low (+), moderate $(++)$ or intense $(+++)$. For this purpose, we used the morphometry software (NIS-Elements D 2.30, Laboratory Imaging s.r.o., Prague, Czech Republic) that allowed us to apply a semi-automated method able to differentially assess positive and negative Gal-3 expressing cells by detecting different intensities and counting positive Gal-3 expressing cells.

Statistical analysis. The relationship between the two markers expression and clinical parameters was evaluated using Pearson's chi-square test. $p$-Values of less than 0.05 values were considered statistically significant. All statistical analysis was performed using the SPSS 22.0 software for Windows 8 .

\section{Results}

Clinical characteristics. Our study included samples from 34 patients composed of 17 (50\%) males and 17 (50\%) females, aged between 30-77 years (mean=55.05). Based on to the World Health Organization histologic classification of kidney tumors (1), $19(56 \%)$ cases were classified as papillary carcinomas and $15(44 \%)$ cases as chromophobe carcinomas.

All tumors were graded according to Fuhrman system and were divided into three groups: grade 1 (4 cases), grade 2 ( 24 cases), grade 3/4 (6 cases). Tumor stages were classified according to TMN classification of renal tumors as follows: I (16 cases), II (10 cases), III/IV ( 8 cases).

The median tumor diameter was $5.9 \mathrm{~cm}($ range $=2.5-6.3 \mathrm{~cm})$. Tumor necrosis was observed in 23 cases $(68 \%)$ and 6 patients $(17.6 \%)$ had renal venous extension. All selected patients underwent partial (27 cases, $79 \%$ ) or total nephrectomy (7 cases, 21\%).

Immunohistochemical findings. Immunohistochemical analysis of Gal-3 in tumor cells showed 3 patterns of expression: membranous, cytoplasmic and nuclear staining (Figure 1) (Table I).

Most of the tumors included in our study showed a cytoplasmic staining of Gal-3 (28 cases, $82 \%$ ), and it was mostly identified in male patients (16 cases/57\%), $(p=0.009)$. Out of 28 cases that expressed Gal-3, 16 tumors (57\%) were papillary carcinomas, while 12 cases $(43 \%)$ were chromophobe carcinomas.

Membranous staining was identified in 20 tumors (59\%). This pattern was predominately found in chromophobe carcinomas (14 cases $/ 70 \%)$, compared with papillary ones (6 cases $/ 30 \%),(p=0.000)$. Another significant correlation was found between high scores of Gal-3 and male patients (14 cases $/ 70 \%),(p=0.028)$.

Nuclear staining of Gal-3 was found in 13 tumors (38\%), commonly in chromophobe carcinomas (9 cases/70\%), compared with papillary ones (4 cases/30\%), $(p=0.005)$. Typically, Gal-3 nuclear expression was stronger in tumors with high Fuhrman grade tumors and was significantly associated with high tumor stages $(p=0.016$ and $p=0.032$, respectively). Gal-3 expression of ppRCC and chRCC stratified by Fuhrman grade and tumor stage is shown in Tables II and Table III, respectively.

An intense Gal-3 expression was observed in the foamy macrophages, but in only 3 cases $(16 \%)$ of papillary subtype. In adjacent non-tumoral tissue, Gal-3 showed intense staining in the ductal, thin and collecting tubules, while the renal glomeruli and proximal tubules were negative for this marker.

\section{Discussion}

In the present study, we analyzed the immunohistochemical expression of Gal-3 in 34 consecutive cases of non-ccRCCs. Gal-3 showed different patterns of expression including nuclear, cytoplasmic and membranous. Consistent with previous studies $(19,20)$, cytoplasmic expression was the most common pattern identified in our cases and it was almost equally distributed between the histological subtypes (43\% chromophobe carcinomas and 57\% papillary carcinomas). By contrast, nuclear and membranous 
expressions were mainly identified in chromophobe tumors (70\% and $70 \%$, respectively).

Predominantly located in the cytoplasm of the cell, Gal-3 maintains cell survival by blocking the intrinsic apoptotic pathway, but it can also shuttle into the nucleus and play a role in cell proliferation $(21,22)$. Additionally, this lectin can be secreted in the extracellular space and due to its ability to interact with the cell surface and with the extracellular matrix, Gal-3 regulates various cellular events (22). Previous data have indicated that Gal-3 contributes to tumor progression and metastasis in a relatively large spectrum of tumors, but depending on its cellular distribution (23). For instance, cytoplasmic overexpression of Gal-3 in tongue and prostate cancer was correlated with advanced disease $(24,25)$, while elevated nuclear expression of Gal-3 was an independent predictor of recurrence in patients with lung cancer (26).

In clear cell RCC tissues, Gal-3 was found to be strongly expressed compared to non-tumorous surrounding tissues, and its elevated levels were correlated with a poor prognosis (19, $20,23,27)$. By contrast, a group of investigators reported that Gal-3 expression is lost during renal carcinogenesis, contributing to a reduced survival rate in patients with ccRCC (28). These discrepancies could be explained by the different methods used for identification of Gal-3. However, Straube and co-workers demonstrated that changes in the cellular level of Gal-3 expression influence the development of clear cell RCC, and when compared with normal tissues, they noticed an increased accumulation of this lectin in the nuclei of tumor cells (23). In the present study, Gal-3 was mainly distributed in cells cytoplasm, yet, only nuclear expression was associated with a high tumor stage $(p=0.032)$ and a high Fuhrman grade $(p=0.016)$. Previous studies showed that Gal-3 is overexpressed in chRCC subtype, but none of them identified a relation with conventional histological parameters. An explanation is that due to their low occurrence, non-ccRCCs were frequently excluded from previous studies or when they were included, the number of cases was small. The increased expression of Gal-3 that we identified in the distal renal tubes supports the traditional theory that chromophobe carcinoma originates from these structures (29).

The prognostic significance of pathological grading in non-ccRCCs is still debated. In a recent study, Borgmann et al. assessed the impact of Fuhrman grade in the largest series of ppRCCs and found that grading of this subtype has a strong prognostic value (30). The International Society of Urological Pathology (ISUP) recommends that grading should be applied only to ccRCC and ppRCC subtypes (31). Chromophobe carcinoma usually shows nuclear pleomorphism, irregular nuclei and nucleolar prominence, thus, most cases have a higher nuclear grade compared with conventional RCC (32). However, one of the largest studies to date compared tumor features of chRCC with those of ccRCC, and found that these entities do not differ in terms of Fuhrman grade and that the less aggressive behavior of chromophobe subtype is not related to pathological grading (33). Surprisingly, most chRCCs $(62.4 \%)$ included in their study were moderately differentiated (G2), while only $19.1 \%$ were poorly differentiated (G3/G4) (33). We obtained comparable results ( $60 \%$ of $\mathrm{G} 2$ and $27 \%$ of $\mathrm{G} 3 / \mathrm{G} 4)$, even if our cohort was considerably smaller than theirs.

Previous data have indicated that there is a male predominance in conventional and papillary variants, while in chromophobe carcinoma this association is less pronounced $(33,34)$. We found that cytoplasmic and membranous Gal-3 expressions were significantly correlated with male patients ( $p=0.000$ and $p=0.005$, respectively). However, nuclear distribution was not associated with gender in our cohort.

Taken together, our results indicate that the nuclear expression of Gal-3 has an essential role in the development of chromophobe carcinoma. The association with advanced tumor stage and nuclear grade suggests that this protein is an indicator of aggressiveness in chRCC. However, further studies on larger cohorts are necessary to enhance the understanding regarding Gal-3 mechanism in non-ccRCCs that may lead to validation of Gal-3 as a prognostic marker in this particular group of patients. Furthermore, targeting anti-nuclear transport may prove an effective therapy for patients with chromophobe RCC.

\section{Acknowledgements}

The present work was supported by funds kindly provided by Victor Babes University of Medicine and Pharmacy Timisoara Romania through internal project PIII-C3-PCFI-2016/2017-01, Multimodal and interdisciplinary approach of antiangiogenic and antivascular therapy resistance in renal cell carcinomas, acronym RCC- AMIRA.

\section{References}

1 Eble JN, Sauter G, Epstein JI and Sesterhenn I: Pathology and Genetics of Tumours of the Urinary System and Male Genital Organs. Lyon, France, IARC Press, 2004.

2 Vera-Badillo FE, Conde E and Duran I: Chromophobe renal cell carcinoma: A review of an uncommon entity. Int J Uro 19: 894900, 2012.

3 Chen SC and Kuo PL: The Role of Galectin-3 in the Kidneys. Int J Mol Sci 17: 565, 2016.

4 Gao X, Balan V, Tai G and Raz A: Galectin-3 induces cell migration via a calcium-sensitive MAPK/ERK1/2 pathway. Oncotarget 5: 2077-2084, 2014.

5 Inohara $\mathrm{H}$, Akahani $\mathrm{S}$, Koths $\mathrm{K}$ and Raz A: Interactions between galectin-3 and Mac-2-binding protein mediate cell-cell adhesion. Cancer Res 56: 4530-4534, 1996.

6 Chen HY, Fermin A, Vardhana S, Weng IC, Lo KFR, Chang EY, Maverakis E, Yang RY, Hsu DK, Dustin ML and Liu FT: Galectin-3 negatively regulates TCR-mediated CD4+ T-cell activation at the immunological synapse. Proc Natl Acad Sci USA 106: 14496-14501, 2009.

7 Yang RY and Liu FT: Galectins in cell growth and apoptosis. Cell Mol Life Sci 60: 267-276, 2003. 
8 Kim H, Lee J, Hyun JW, Park JW, Joo HG and Shin T: Expression and immunohistochemical localization of galectin-3 in various mouse tissues. Cell Biol Int 31: 655-662, 2007.

9 Saussez S, Lorfevre F, Lequeux T, Laurent G, Chantrain G, Vertongen F, Toubeau G, Decaestecker C and Kiss R: The determination of the levels of circulating galectin-1 and -3 in HNSCC patients could be used to monitor tumor progression and/or responses to therapy. Oral Oncol 44: 86-93, 2008.

10 Miranda FA, Hassumi MK, Guimarães MCM, Simões RT, Silva TGA, Lira RCP, Rocha AM, Mendes CT, Donadi EA, Soares CP and Soares EG: Galectin-3 Overexpression in Invasive Laryngeal Carcinoma, Assessed by Computer-assisted Analysis. J Histochem Cytochem 57: 665-673, 2009.

11 Buttery R, Monaghan H, Salter DM and Sethi T: Galectin-3: differential expression between small-cell and non-small-cell lung cancer. Histopathology 44: 339-344, 2004.

12 Cheng D, Liang B and Li Y: Serum Galectin-3 as a Potential Marker for Gastric Cancer. Med Sci Monit 21: 755-760, 2015.

13 Arfaoui-Toumi A, Kria-Ben Mahmoud L, Ben Hmida M, Khalfallah MT, Regaya-Mzabi S and Bouraoui S: Implication of the Galectin-3 in colorectal cancer development (about 325 Tunisian patients). Bull Cancer 97: E1-E8, 2010.

14 Sumana BS, Shashidhar S and Shivarudrappa AS: Galectin-3 immunohistochemical expression in thyroid neoplasms. J Clin Diag Res 9: EC07-EC11, 2015.

15 Zhang L, Wang P, Qin Y, Cong Q, Shao C, Du Z, Ni X, Li P and Ding K: RN1, a novel galectin-3 inhibitor, inhibits pancreatic cancer cell growth in vitro and in vivo via blocking galectin-3 associated signaling pathways. Oncogene 36: 1297-1308, 2017.

16 Vanden Brule FA, Buicu C, Berchuck A, Bast RC, Deprez M, Liu FT, Cooper DNW, Pieters C, Sobel ME and Castronovo V: Expression of the $67-\mathrm{kD}$ laminin receptor, galectin-1, and galectin-3 in advanced human uterine adenocarcinoma. Hum Pathol 27: 1185-1191, 1996.

17 Castronovo V, VandenBrule FA, Jackers P, Clausse N, Liu FT, Gillet $\mathrm{C}$ and Sobel ME: Decreased expression of galectin-3 is associated with progression of human breast cancer. J Pathol 179: 43-48, 1996.

18 Califice S, Castronovo V, Bracke M and van den Brule F: Dual activities of galectin-3 in human prostate cancer: tumor suppression of nuclear galectin-3 vs. tumor promotion of cytoplasmic galectin-3. Oncogene 23: 7527-7536, 2004.

19 Xu Y, Li C, Sun J, Li J, Gu X and Xu W: Antitumor effects of galectin-3 inhibition in human renal carcinoma cells. Experimental Biology and Medicine 241: 1365-1373, 2016.

20 Jane Y. Dancer, Luan D. Truong, Zhai Q and Shen SS: Expression of Galectin-3 in Renal Neoplasms: A Diagnostic, Possible Prognostic Marker. Archives of Pathology \& Laboratory Medicine 134: 90-94, 2010.

21 Davidson PJ, Davis MJ, Patterson RJ, Ripoche MA, Poirier F and Wang JL: Shuttling of galectin-3 between the nucleus and cytoplasm. Glycobiology 12: 329-337, 2002.

22 Haudek KC, Spronk KJ, Voss PG, Patterson RJ, Wang JL and Arnoys EJ: Dynamics of Galectin-3 in the Nucleus and Cytoplasm. Biochim Biophys Acta 1800: 181-189, 2010.

23 Straube T, Elli AF, Greb C, Hegele A, Elsasser HP, Delacour D and Jacob R: Changes in the expression and subcellular distribution of galectin-3 in clear cell renal cell carcinoma. J Exp Clin Cancer Res 30: 89, 2011.

24 Honjo Y, Inohara H, Akahani S, Yoshii T, Takenaka Y, Yoshida J, Hattori K, Tomiyama Y, Raz A and Kubo T: Expression of cytoplasmic galectin-3 as a prognostic marker in tongue carcinoma. Clin. Cancer Res 6: 4635-4640, 2000.

25 van den Brûle FA, Waltregny D, Liu FT and Castronovo V: Alteration of the cytoplasmic/nuclear expression pattern of galectin-3 correlates with prostate carcinoma progression. Int $\mathbf{J}$ Cancer 89: 361-367, 2000.

26 Mathieu A, Saal I, Vuckovic A, Ransy V, Vereerstraten P, Kaltner H, Gabius HJ, Kiss R, Decaestecker C, Salmon I and Remmelink $\mathrm{M}$ : Nuclear galectin-3 expression is an independent predictive factor of recurrence for adenocarcinoma and squamous cell carcinoma of the lung. Mod Pathol 18: 1264-1271, 2005.

27 Von Klot C-A, Kramer MW, Peters I, Hennenlotter J, Abbas M, Scherer R, Herrmann TRW, Stenzl A, Kuczyk MA, Serth J, and Merseburger AS: Galectin-1 and Galectin-3 mRNA expression in renal cell carcinoma. BMC Clin Pathol 14: 15, 2014.

28 Merseburger AS, Kramer MW, Hennenlotter J, Serth J, Kruck S, Gracia A, Stenzl A and Kuczyk MA: Loss of galectin-3 expression correlates with clear cell renal carcinoma progression and reduced survival. World J Urol 26: 637-642, 2008.

29 Young AN, Amin MB and Neish AS: Expression profiling of renal epithelial neoplasms: a method for tumor classification and discovery of diagnostic molecular markers. Am J Pathol 158: 1639-1951, 2001.

30 Borgmann H, Musquera M, Haferkamp A, Vilaseca A, Klatte T, Shariat SF Scavuzzo A, Jimenez Rios MA, Wolff I, Capitanio U, Dell'Oglio P, Krabbe LM, Herrmann E, Ecke T, Vergho D, Huck N, Wagener N, Pahernik S, Zastrow S, Wirth M, Surcel C, Mirvald C, Prochazkova K, Hutterer G, Zigeuner R, Cindolo L, Hora M, Stief CG, May M and Brookman-May SD: Prognostic significance of Fuhrman grade and age for cancer-specific and overall survival in patients with papillary renal cell carcinoma: results of an international multi-institutional study on 2189 patients. World J Urol, 2017. doi: 10.1007/s00345-017-2078-5. [Epub ahead of print]

31 Delahunt B, Cheville JC, Martignoni G, Humphrey PA, MagiGalluzzi C, McKenney J, Egevad L, Algaba F, Moch H, Grignon DJ, Montironi R and Srigley JR: The International Society of Urological Pathology (ISUP) grading system for renal cell carcinoma and other prognostic parameters. Am J Surg Pathol 37: 1490-1504, 2013.

32 Amin MB, Amin MB, Tamboli P, Javidan J, Stricker H, de-Peralta Venturina M, Deshpande A and Menon M: Prognostic impact of histologic subtyping of adult renal epithelial neoplasms: an experience of 405 cases. Am J Surg Pathol 26: 281-291, 2002.

33 Steffens S, Roos FC, Janssen M, Becker F, Steinestel J, Abbas M, Steinestel K, Wegener G, Siemer S, Thüroff JW, Hofmann R, Stöckle M, Schrader M, Hartmann A, Junker K, Kuczyk MA and Schrader AJ: Clinical behavior of chromophobe renal cell carcinoma is less aggressive than that of clear cell renal cell carcinoma, independent of Fuhrman grade or tumor size. Virchows Arch 465: 439-444, 2014.

34 Patard JJ, Leray E, Rioux-Leclercq N, Cindolo L, Ficarra V, Zisman A, De La Taille A, Tostain J, Artibani W, Abbou CC, Lobel B, Guillé F, Chopin DK, Mulders PF, Wood CG, Swanson DA, Figlin RA, Belldegrun AS and Pantuck AJ: Prognostic value of histologic subtypes in renal cell carcinoma: a multicenter experience. J Clin Oncol 23: 2763-2771, 2005.

Received October 11, 2017

Revised November 1, 2017

Accepted November 2, 2017 